\title{
VIRTUAL LEARNING: THE AFFECTS OF COVID-19 ON RURAL STUDENT AND TEACHER ENGAGEMENT
}

\author{
Chloe Papavasiliou ${ }^{1}$ and Samantha Papavasiliou ${ }^{2}$ \\ ${ }^{1}$ South Australian Department of Education, Adelaide, Australia \\ ${ }^{2}$ Adelaide Business School, University of Adelaide, Adelaide Australia
}

\begin{abstract}
The impacts of COVID-19 on education have been profound. This impact has changed how many schools and education providers have delivered education to their students, with the rapid transition to virtual learning environments. This research highlights the critical factors influencing student and teacher engagement and opportunities for educators to enhance the engagement for their students. Evidence for this research is based on the results of a case study on a rural school district in South Australia, data collected through two focus groups. By understanding the critical factors influencing teacher and student engagement in the rural setting, to identify opportunities for improving the levels of student engagements through virtual learning environments. A primary finding of this research highlights three critical factors; access, learning needs and support, which influence the levels of engagement of teachers and students in the rural setting. This research identifies the opportunities outlined by the respondents for increasing student engagement, this included peer-to-peer mentoring and resource sharing opportunities. By understanding the impacts of COVID-19 on student and teacher engagement, relating to the rapid introduction of virtual learning, potentially can assist future research and educators understand how to improve the process moving forward.
\end{abstract}

\section{KEYWORDS}

Curriculum Content Design \& Development, Delivery Systems and Environments, Virtual Learning Environments, Blended Learning

\section{INTRODUCTION}

COVID-19 is an unprecedented crisis, impacting all countries and sectors differently. Education saw significant closures of face-to-face activities within all types of educational institutions, across 190 countries in order to either prevent or decrease the spread of the virus (ECLAC 2020). This was felt within Australia, where many early learning centres, and junior and secondary schools closed and had to rapidly transition their teachers and students to remote learning (PWC 2020). Research demonstrates that not all students were affected equally, this could relate to socioeconomic status, location (especially rural students) or support networks at home (ECLAC 2020). Furthermore, the impacts on the development of cognitive and non-cognitive skills (both positively and negatively) are unknown, and the affects could cause consequences and opportunities in both the short and long term (Schleicher 2020). It is clear that there are a number of unknowns associated with the implications of shifting education online for both student and teacher engagement.

In response to the first wave of COVID-19, the Australian Federal and State Governments implemented virtual learning systems, either encouraging or mandating virtual learning for all students in primary or secondary schools (Hendry 2020). This decision was made quickly, in response to the rapidly changing environment, and having significant impacts on teachers and students ability to engage and interact with one another (Hendry 2020; Zagon 2020). Along with the stresses associated teachers having to rapidly implement virtual learning, teachers were also required to incorporate the various learning needs and styles of their students (Zagon 2020). Students are also impacted significantly by the implementation of virtual learning, students require ongoing support from both an education and mental health standpoint to ensure positive outcomes (Zagon 2020). 
This study focuses on the implications of COVID-19 and the implementation of virtual and blended learning approaches. For this study, rural schools incorporate all schools and educational facilities which are not located within an Australian major city. Furthermore, rural and remote are used as interchangeable terminology within this research and previous literature consulted. Previous research identifies a number of disadvantages impacting students and teachers of rural schools, including; reduced staffing numbers, decreased funding and resources, breadth of the education program offered, overall school size and ability to obtain additional parental support and involvement in the school (Lamb, Glover and Walstab 2014).

A further review of the literature demonstrates that there are challenges present for the use of virtual learning platforms and student engagement. This includes the delivery of the material, providing equal opportunities for all students to learn and have their learning styles and needs addressed (Dale and Lane 2007). Educational engagement literature demonstrates how teachers must consider three factors (cognitive, behavioural and emotional) of student engagement to ensure successful educational outcomes of students (Ainley, Enger \& Searle 2008). Therefore, this research seeks to explore if the previously identified challenges facing rural schools has confounding impacts of student and teacher engagement when utilising virtual learning.

This study aims to highlight several impacts on both student and teacher engagement as a result of the transition to online education. Utilising a case study on a rural school district in Northern South Australia. This research collected data from 2 focus groups. The purpose of these focus groups was to seek feedback and experiences from teachers affected by the first wave of the COVID-19 pandemic and the changes to education delivery in rural schools. The overarching research aim was to understand if blockers to engagement (both teacher and student) were identified, what they were and how they could be overcome if digital education was implemented again or as part of the norm. Three primary research questions were developed:

1) Are there any critical factors influencing teacher and student engagement?

2) What are the primary factors impacting student and teacher engagement with online/virtual learning in rural schools during COVID-19?

3) What opportunities can be adopted by educators to enhancing the digital engagement experience in the behaviours of their students?

As a result of the focus groups and in response to the three research questions, a Gioia analysis highlighted 3 primary categories which were identified as either positively and negatively impacting both student and teacher engagement. Gioia was applied to this research to help bring order and meaning to the responses from the respondents, specifically to identify the critical factors outlined in the responses provided by the students and teachers.

As the transition to digital education occurred quickly, many teachers and students reported that they were poorly equipped to respond. This includes having access to technology and internet services from home. For teachers, the impacts of digital/online learning were felt across multiple areas of teacher's workload. Firstly, how teachers designed and developed their curriculum content, to be suited to the online environment. Teachers had to quickly adapt and develop content that was easily understood and engaging for students, within these online environments. Not every teacher was prepared to do this. Secondly, the delivery systems and environment changed quickly. Teachers and students were dealing with new environments for learning (e.g. from home or within the parental workplace) and the delivery system changes (e.g. zoom or Microsoft teams). Prior to COVID-19, each teacher had varying skill levels and experience using digital delivery systems as part of their day-to-day teaching practices. Impacting their ability, speed and willingness of adopting and using these systems during COVID. Teachers with greater experience stated that they were more confident and able to use the services and deliver engaging content to students within these mediums, while also remaining engaged themselves.

This paper is divided into six sections. Section one contains the introduction, section two presents the literature review, section three outlines the research methods undertaken, section four highlights the results and addresses the research questions, and section five offers potential implication for policy makers in the education sector. 


\section{LITERATURE REVIEW}

In the relatively short time since its inception, the COVID-19 pandemic has presented unprecedented challenges to global governments and impacted many aspects of our lives. The virus created a situation in which the learning environment for all students, regardless of level, location or socioeconomic status were quickly changed from a classroom based to virtual learning environment. Forcing many students to undertake their mandatory schooling in isolation at home. Although, this was essential to prevent the spread of infection, there were a number of issues which impacted students and educators mental and social well-being, as well as their ability to undertake everyday classroom activities. Not only did isolation impact the overall well-being of students, the sudden change created challenges for educators to not only create, but select and provide appropriate learning environments for students.

These challenges were further escalated in rural and remote education environments of Australia, already impacted by limited digital access; which can be discussed in relation to accessibility, awareness, appropriateness and affordability of digital inclusion (Featherstone, 2015). Although a PISA (2003) study found no real significant difference in access to ICT between metropolitan and non-metropolitan schools in Australia, limited digital access has been well documented in rural and remote areas (Ainley \& Enger, 2020; Guenther, Smede \& Young, 2020). Limited digital access instigates a cycle whereby students have limited access to a computer which decreases ability to obtain skills and knowledge, thereby decreasing awareness of use (Guenther, Smede \& Young, 2020). This can be further exacerbated by studying in the home environment, where there is decreased teacher and student interaction and an increased necessitated collaboration between parents and children (Bhamani, Makhdoom, Bharuchi, Kaleem \& Ahmed, 2020). Especially relevant, as the level of parental support varies from student-to-student and is difficult to measure and provide assistance with (Wyse, Hills, Stickney, Butz, Beckler \& Close, 2020). Levels of parental support is also impacted by the level of digital knowledge, skills and accessibility and is dependent to a degree, upon the parent's age, level of education attained, socio-economic status, social and family-related factors (Wyse, Hills, Stickney, Butz, Beckler \& Close, 2020). Although these issues are not new, nor the fault of the parent, their impact has been more easily identified by teachers, students and parents. It is important to note, that these factors add another impact layer of student engagement, interest in schooling and ability to perform well in educational settings without their normal level of teacher support.

Information and Communication Technologies (ICT) was already changing the learning experience for students prior to the outbreak of COVID-19, with the unlimited potential of virtual learning environments well recognised (Ainley \& Enger, 2020). However, COVID-19 necessitated a sudden shift to use of ICT in the home environment, which provided challenges to educators. Research on educational engagement has highlighted three forms of engagement; behavioural, emotional and cognitive which can be related directly to use of ICT (Ainley \& Enger, 2020). Behavioural refers to participation in use of digital technologies, emotional refers to student attitudes and motivation to use of ICT and cognitive to the influence ICT has on outcomes of learning (Ainley \& Enger, 2020). All forms of engagement are negatively impacted by family and environment factors and are directly related to an assumption that because students understand how to use the internet in everyday life, that they are digitally skilled in an online educational format (Helsper \& Eynon, 2013; Wyse, Hills, Stickney, Butz, Beckler \& Close, 2020). Teachers were placed in a position of suddenly transferring learning environments to an online format, whilst maintaining appropriate learning and maintaining student engagement. There is a view that current students are 'digital natives', born into a technology-rich environment and thereby in possession of the digital skills required to navigate a change in educational format (Bergdahl, Nouri, Fors \& Knutsson 2020). However, being digitally literate, does not necessarily equate to being in possession of the necessary digital skills, or having access to a computer or effective internet (Guenther, Smede \& Young, 2020). Therefore, researchers need to explore and understand the various factors which impact not only student and teacher engagement with the virtual classroom content, but also their ability to interact and respond to the changing environment.

\subsection{Digital Engagement and Virtual Learning}

There is considerable research on educational engagement in both students and teachers, this research explores the implications of location, socioeconomic status, student level and teachers capabilities. With the rapidly changing environment prior to and during COVID-19, there has been an increased interest in understanding 
how engagement is impacted by the social and environmental changes occurring in the global community. Research has shown that student engagement is multidimensional with a close connection to student performance (Virtanen, Lerkkanen, Poikkeus \& Kuorelahti, 2013; \& Shernoff, Kelly, Tonks, Anderson, Cavanagh, Sinha, Abdi, 2016). Literature has categorised student engagement into three factors; behavioural, emotional and cognitive (Ainley, Enger \& Searle 2008; Shernoff et al 2016). The literature shows the importance of considering all three of these engagement factors to ensure that students are both challenged and engaged, thus ensuring a successful student engagement. As a result of higher levels of student engagement, teachers often report being more engaged themselves.

Understanding how to increase student engagement has been a key element of educational research for the last 2 decades at least, however the focus has started to shift to explore the role of digital factors in students engagement or disengagement with the classroom. Information and communication technologies (ICT) have a signification influence on today's classroom environments dramatically shifting learning methods (Al-Rahmi, Alzahrani, Yahaya, Alalwan \& Kamin, 2020). Students regularly have access to and connect with ICT in different forms, and has significantly changed how teachers provide access to all students within the classroom setting. Vygotsky (1926) discussed the "learning is a social and transactional process occurring between individuals, mediated through language and other cultural tools, in the context of a sociohistorical influenced environment". The impacts of COVID-19 causing the transition to virtual learning environments, has demonstrated the increased complexities for educators and teachers to provide education that is engaging for both teachers and students.

Virtual learning is becoming increasingly common within education systems as technology develops and impacting how students engage with it (Dale \& Lane, 2007). To support students learning it is vital that teachers employ a range of learning strategies not only for engagement but student outcomes. This is becoming more apparent with larger class sizes which brings a more diverse learning cohort that teachers need to take into account (Hussain, Zhu, Zhang and Abidi 2018). Virtual learning takes on many different forms and can be accessible by more students with the added benefit of multiple stakeholders being able to access and monitor student development and engagement (Leese, 2009). Students individual learning abilities are able to be taken into account by allowing students to access work which suits their learning abilities in the unit, this can be achieved through the creation of online pre and post testing and formative tasks throughout the unit (Leese, 2009). Therefore, teachers need to factor in the varieties of learning management and content delivery systems against the engagement of their current cohort and how accessible the platform would be (Hussain et al, 2018). Meaningful task development of the materials needed, blended activities (discussions, video conferencing, etc) and feedback (timing and delivery) is crucial to the success for student engagement in virtual learning as literature has shown that there is less engagement in this form of learning (Hussain et al, 2018; Ahmed, Shehata, Hussain 2020). Teachers need to be aware that a key component of an engaging virtual teaching environment is having discussions and creating meaningful and purposeful talks/discussion to gage student engagement as well as development and understanding in the topic (Hussain et al, 2018; Ahmed et al, 2020). Feedback is vital for the success of this online blended model, feedback not only from students but other stakeholders as well as self-reflection with student formative and summative work to see where engagement was starting to drop (Ahmed et al, 2020). It is important to note, that many of the challenges faced by rural students and educators, were not triggered by COVID-19. However, the complexities provided by the rural environment and school setting in Australia, had a significant impact on the challenges faced by these students when facing the virtual learning environment, especially when considering student engagement levels.

\section{METHOD}

The motivation for this study originated from a desire to understand the implications of COVID-19 on rural education and engagement in Australia A comprehensive literature review of research centred on engagement has revealed that through drastic change and without adequate support, there is a lack of inclusiveness in the delivery of online or digital education, regardless of location. However, rural students are impacted by a number of different challenges, including reduced staffing numbers, decreased funding and resources, breadth of the education program offered and overall school size (Lamb et al 2014). The method outlined below outlines how the analysis provided addresses the research questions. 


\subsection{Case Study}

The use of a case study method has been applied to this research to understand the different issues affecting digital education in the South Australian rural schools during COVID-19. The South Australian Rural school case study was selected as historically they receive decreased levels of support (including student support officers), less resources (e.g. equipment), decrease breadth of curriculum provided (Lamb et al 2014) and have less significantly less students than regional and major city schools (as outlined in Table 1).

Table 1. Number of students in Senior Schools in South Australian Regions (Australian Bureau of Statistics 2020)

\begin{tabular}{lll}
\hline Location & Count & $\%$ \\
\hline Rural & 8,855 & $3.26 \%$ \\
Regional & 59,357 & $21.86 \%$ \\
Major City & 203,354 & $74.88 \%$ \\
\hline
\end{tabular}

A qualitative approach was applied to this research, which was appropriate for this study. This research carried out exploratory qualitative data analysis using Gioia's method for Qualitative rigour, to understand results from the data collection. This approach was applied to obtain an understanding of critical factors influencing student and teacher engagement and the opportunities they present for the future. The starting point for this research analysis involved a qualitative method to explore and understand the different meanings and themes individuals or groups link to a problem (Goddard and Melville 2004). An inductive approach was applied to this research, which involved a process of searching for patterns within observations, which was then used to develop explanations or theories, and from which a series of hypotheses were created (Bernard 2011; Bird, Klein and Loper 2009). The application of an inductive approaches allowed for the emergence of research questions to assist in the identification of themes within the results.

Data collection for this study occurred as part of two focus groups in September 2020, each of 6 (12 participants total). This included asking 12 secondary teachers from rural schools affected by COVID-19 and implemented virtual learning. As part of these focus groups, teachers were asked about their students and their personal experiences. The questions posed within the focus group were qualitative and open-ended, designed in a manner to explore different components and facets of the issues faced by respondents. The focus group queried the challenges that teachers, students and parents faced, including support, resources and digital technology.

Post data collection, data was anonymised and categorised based on areas of interest. The first analysis, utilised a Gioia analysis of collected qualitative data, the critical factors impacting student and teacher engagement. The study findings address specific factors in relation to the challenges and opportunities faced during the COVID-19 period. The key questions used in the focus group are provided in Table 2 .

Table 2. Example of the questions used in the focus groups and the themes they were addressing

\begin{tabular}{|c|c|}
\hline Questions & Themes and Factors \\
\hline What limits & Support, Access, Lea \\
\hline ng? & Lea \\
\hline $\begin{array}{l}\text { Did you find that you had enough support to ensure work was created or } \\
\text { recreated online? Why/ Why not? }\end{array}$ & Support, Access \\
\hline Were students appropriately equipped to study from home? & Supp \\
\hline What opportunities are there for the future if this was to happen again? & Support, Access, Learning Needs \\
\hline
\end{tabular}

\subsection{Gioia Analysis}

As previously outlined, the Gioia's method for qualitative rigour was utilised to analyse the data. This enabled the researches to find structure in unstructured qualitative forms, as it is a systematic approach. The Gioia method (Gioia, Corley and Hamilton 2012; Gioia and Chittipeddi 1991) requires the researcher to step back, and then categorise the accounts into three different phases (First, Second and Third order). The first order, 'Concepts', is the 'voice of the user' (also known as 'voice of the customer'). The second order, 'concerns and statements', identifies specific sentences from participants which are then grouped together to discover the themes and patterns in events and accounts. These create themes that are more generalised underlying explanatory dimensions, to test consistency and patterns (Gioia et al 2012; Gioia and Chittipeddi 1991). Finally, 
the third order 'aggregate dimensions', identifies the generic themes encompassing all of the first and second order data (Gioia et al 2012; Gioia and Chittipeddi 1991. Significance was measured through counting occurrences of first, second and third order elements to identify themes and patterns throughout the different accounts. The patterns in the text were then linked by connections, highlighting key features and emergent concepts or themes that require further analysis. Our analysis will focus on understanding if there are any critical factors influencing student and teacher engagement, while also discussing the opportunities for educators to utilise digital education to improve student engagement going forward.

\section{RESULTS}

Results from this research demonstrate that there are three categories of critical factors impacting both teacher and student engagement during COVID-19 virtual learning changes. Access to required sources, equipment and technology was the first. The second was available support from parents, teachers, schools/department and fellow teachers. Finally, learning needs which included engagement requirements, learning needs and feeling/being equipped to implement and use the virtual learning systems. These results will be discussed in detail in the following section.

\subsection{Results from Gioia Analysis - Factors Impacting Student Engagement}

The results of the Gioia analysis outlined in Figure 1 outlines the factors associated with student engagement. Addressing research question 1 and 2, the analysis demonstrates that respondents identified three specific elements affecting the levels of personal and student engagement during COVID-19 digital education. Identifying that rural students reported having poor and inconsistent access to online material, virtual learning systems, digital technology and internet. Respondents reported that poor access had considerable impacts of the levels of engagement of students during this period. Although, students were provided access to required technology as quickly as possible, with schools identifying the need and sourcing laptops and wireless internet for a high percentage of the school cohort. During the focus groups, many respondents reported students feeling shame and embarrassment when requiring school issued technology. For example "it is embarrassing to not own personal devices" or "textbooks and supporting material is expensive and not easy to afford". Many students indicated that they felt by not having personal devices similar to other students in their classes, they were not prepared to succeed and also were seen by their peers as unworthy of additional support or assistance. This had a significant impact on their reported levels of engagement, including their success during assessments both formative and summative.

In addition, the impacts of varying levels of support offered to students was identified as a key issue impacting their engagement. This included parental support for students, including parents ability to support students when the teacher was not available. With respondents stating "Parents do not understand the content" or "students role included upskilling parents to ensure they could support their children's education". This change in role put additional pressure on both students and parents, especially in primary level education. Although schools and teachers did their best to support both students and parents, during the peak COVID-19 lockdowns, students reported feeling isolated and in some cases forgotten. Especially when it came to having one on one support from their teachers and student support officers.

Students within each of the classrooms had varying learning needs and learning disabilities, impacting their level of engagement based on the ability of teachers to adapt to the new environment and provide engaging material. For example "disabilities are not always accounted for appropriately" and "not everyone is capable of prepared for virtual learning environments". Students reported engaging content as that which required discussion, used multiple resource types (e.g. games, collaboration and assessment), while content that was delivered in lecture format without discussion or activity was disengaging and often hard to follow. Incorporating multiple different learning needs and styles into a face-to-face environment is already complex, respondents indicated that they often felt poorly equipped to be learning their virtual environments.

Respondents reported feeling greater levels of connection, including peer-to-peer support, who identified an opportunity to interact with students from other schools outside of their district. Thus, encouraging students to collaborate and connect (through a moderated environment) with other students facing similar circumstances, who are from different backgrounds and could provide opportunities for networking. 
Respondents indicated that through virtual learning and online collaboration they had the opportunity to develop study skills, organisation and personal accountability, were they were responsible for ensuring they were getting their education. In addition students were more inclined to ask for help and assistance, after seeing teachers collaborating and asking for help. Students realised it is okay to not be sure of everything. Thus, providing an opportunity for future educational engagement channels for students to implement new collaboration and peer-to-peer support networks.

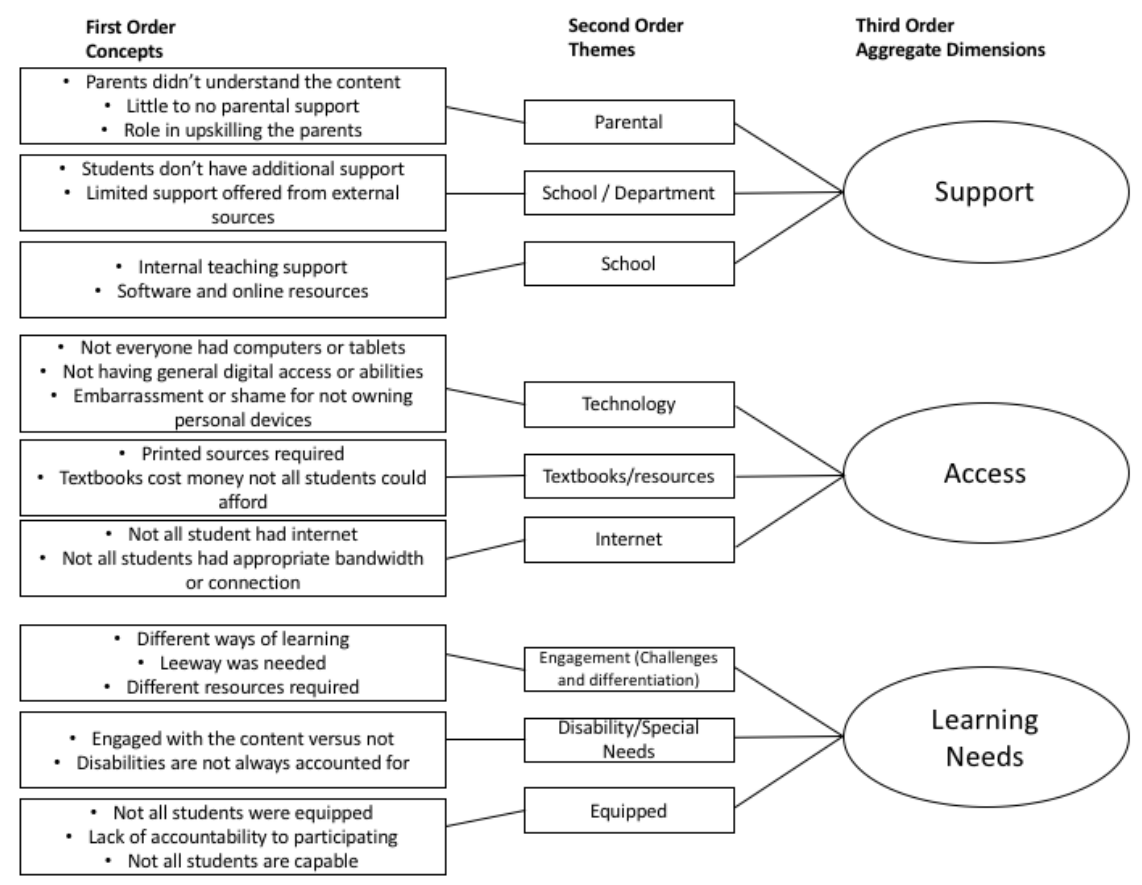

Figure 1. Results of the Gioia Analysis Student Engagement Critical Factors

\subsection{Results from Gioia Analysis - Factors Impacting Teacher Engagement}

Results of the Gioia analysis outlining factors impacting teacher engagement are outline in Figure 2. Addressing research questions 1 and 2, highlighted the same critical factors affecting the levels of personal (teacher) engagement during the COVID-19 virtual learning period to that of student engagement. Interestingly, teachers outlined that they were impacted by having limited access to technology, including owning the necessary technology to utilise multiple virtual systems and resources. In addition teachers outlined the need to have additional training to understand how to best use the systems, in order to engage their students in the most effective and efficient manner. For example "my school has provided access to one virtual system, in a limited capacity making it difficult to share multiple types of resources with students". Another respondent stated "more time was needed to allow teachers to train and upskill on how to best use the technology and virtual learning platforms". Although a number of teachers reported difficulties associated with accessing technology, they also reported greater levels of comradery between teachers sharing their resources to ensure students were adequately engaged. Teachers reported that their engagement came from having access to the necessary tools and technologies, while also having other teachers to seek support and guidance from.

Teachers stated that support was another critical factor influencing their levels of engagement. Changing the role of parents to support roles for both teachers and students, put additional pressure on teachers to ensure that parents were appropriately upskilled. This support was often impacted by whether or not a parent was disengaged themselves or if they were unsure in how they could help their children with learning the content. Teachers reported that due to the climate, the department was limited in the amount of support they could provide the teachers. For example "we understood the department prioritising students, but it was hard for us teachers". Therefore teachers developed greater peer-to-peer networks, utilising online forums and various websites were teachers can discuss issues they are facing and seek guidance from others in similar situations. 
Finally, learning needs was another critical factor influencing teachers engagement. Teachers outlined that they felt they were more engaged when they had the confidence to ask for help and experience using systems. This was similar to students. In addition, teachers felt more engaged when they were able to develop their own content and utilise different resources in order to meet the learning needs of their students. For example "my school encourages us to use different resources and work together for student outcomes". This is similar if they felt they had time to develop content that meet the needs of students with disabilities and special needs. Teachers outlined that they felt more engaged with their role as a teacher, when their students were engaged and they were supported to deliver content which led to positive student outcomes.

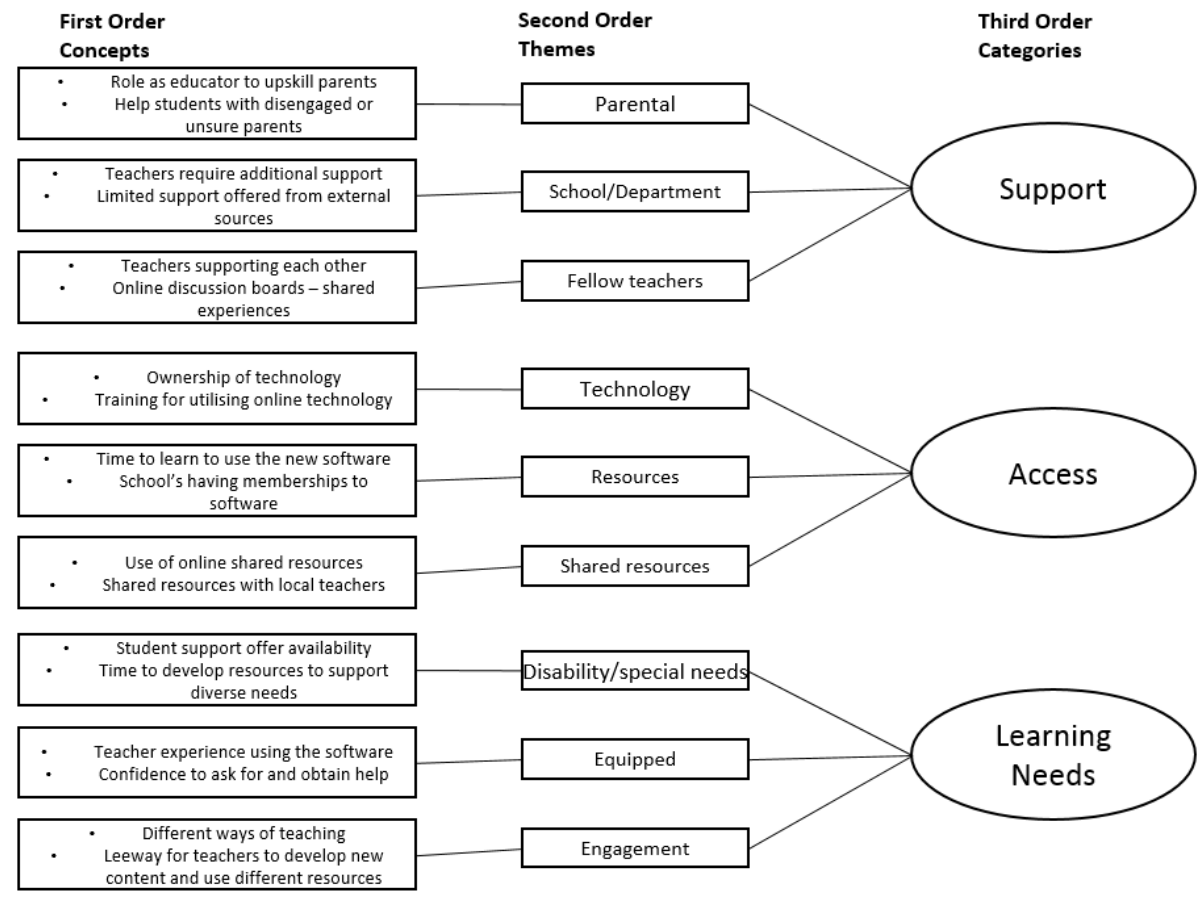

Figure 2. Results of the Gioia Analysis Teacher Engagement Critical Factors

\section{EDUCATION POLICY IMPLICATIONS AND RECOMMENDATIONS}

Responding to the COVID-19 pandemic and the rapid introduction of virtual learning has provided a number of opportunities for educators to develop their skills and understanding in student engagement, especially digital engagement. Teachers identified that although students are technologically savvy now than previous generations, may not actually engage fully, if at all, with online or digital material (Combes 2009). This is the result of the fundamental change in the role of technology in their life, whereby it is used for communication and entertainment purposes (Combes 2009).

The results of the focus groups also demonstrated that teachers enjoyed the increased levels of peer-to-peer support, including the sharing of skills, knowledge and resources in order to improve the learning and engagement outcomes for all students (Moore and Hodges 2020). This shared the burden of being new, innovative and exciting to multiple teachers across the world, rather than expecting one teacher to have the answers to everything, this notion of shared resourcing (Van Acker, Van Buuren, Kreijns and Vermeulen 2013).

Teachers have identified an opportunity arising from this situation to develop their skills in engaging students through digital mediums, as many identified that their students had shorter attention spans. This is common among digitalisation in education research (Weigel, Straughn and Gardner 2010). Although there is an expectation that teachers remain up to date with current trends and technologies, and bring these to their classrooms, upskilling is always necessary (Aubusson and Schuck 2013). The speed in which upskilling was expected during COVID-19 meant that some teachers fell behind. 
Respondents found that resources were limited even in high school, with many students did not have access to a computer or laptop, which was the main way that teachers were not only delivering classes and materials however feedback. Feedback and its timing were deemed critical for the learning process not only for students to understand where to improve and how or where they are achieving but also teachers being able to deliver units at appropriate challenge for students. Students heavily rely on this feedback to keep them motivated to achieve, when this was removed from the learning process teachers then found that students were not handing in work, work was not at appropriate challenge and students disengaged often not attending online classes, interacting in online forums or handing in formative and summative work. Teachers at this site felt overwhelmed and under supported often turning to buying or subscribing to online teaching resource sites to assist with teaching all students. The problem with this is that with the rush to get work out or with the confusion on how students would be able to complete the work unassisted teachers were not adapting these resources rather downloading and printing/uploading. This 'one size fits all' approach further disengaged students, and did not necessarily provide any self-learning opportunities for students to further develop skills rather provided some with 'busy work'.

Future research is recommended, as conducting a study on one rural area school is not an indication of all Australian rural schools. This includes outlining whether or not schools are ensuring all students can equally access learning materials for success (Ainley and Enger 2007). The results of this study raises similar questions to research by Ainley and Enger (2007), which found that there was no significant difference between access to digital technology between metropolitan and non-metropolitan. The question being, are digital technology access issues an issue affecting both metropolitan and non-metropolitan schools equally. In addition, further research is needed to understand the role of information and resource sharing among teachers and also schools, in order to answer whether teachers who shared resources online were more engaged or prepared than those who did not.

\section{ACKNOWLEDGEMENT}

The results and views presented in this paper do not represent the view of the South Australian Department of Education or the Australian Department of Education.

\section{REFERENCES}

Aubusson, P, and Schuck, S, 2013, Teacher education futures: today's trends, tomorrow's expectations, Teacher Development, vol. 17, No. 3, pp. 322-333.

Ainley, J and Enger, L, 2020, Student Use of, and Engagement with, Information Technology, Australian Council for Educational Research.

Ainley, J., and Engers, L, 2007, Student use of, and engagement with, information technology. Curriculum Corporation. Available from: https://research.acer.edu.au/digital_learning/11

Ainley, J et al, 2008, Students in a Digital Age: Implications of ICT for Teaching and Learning. In: Voogt J., Knezek G. (eds) International Handbook of Information Technology in Primary and Secondary Education, Springer, Boston, MA.

Al-Rahmi, W.M et al, 2020, Digital Communication: Information and Communication Technology (ICT) Usage for Education Sustainability, Sustainability, vol. 12, pp. 5052.

Australian Bureau of Statistics, Schools, Available https://www.abs.gov.au/statistics/people/education/schools/latest-release\#schools . Retrieved: 10 November 2020.

Bergdahl, N et al, 2020, Engagement, disengagement and performance when learning with technologies in upper secondary school, Computers \& Education, vol. 149.

Bernard, H.R, 2011, Research Methods in Anthropology (5th Edition), AltaMira Press, United Kingdom.

Bhamani, S et al, 2020, Home Learning in Times of COVID: Experiences of Parents, Journal of Education and Educational Development, vol. 7, No. 1, pp. 9-26.

Bird S, et al, 2009, Natural Language Processing with Python: Analysing Text with the Natural Language Toolkit, O'Reilly Media, United Kingdom.

Cabrera, D, et al, 2007, Systems Thinking, Evaluation and Program Planning, vol.31, No. 3, pp.299-310. 
Combes, B, 2009, Digital natives or digital refugees? Why we have failed Gen Y?, Proceedings of 38th Annual Conference of the International Association of School Librarianship, Albano Terme, Padova, Italy, pp. 1-12.

Creswell, J.W, 2009. Research Design: Qualitative, Quantitative and Mixed Methods Approach (3rd Edition), Sage, LA USA.

ECLAC, 2020, Education in the Time of COVID-19, Economic Commission for Latin America and the Carribean, pp. $1-20$.

Featherstone, D, 2015, Connected, Creative and Cultural Communities: Developing an integrated approach to Policy and Evaluation for Remote Australian Indigenous Media and Communications, Doctor of Philosophy, Murdoch University, Australia.

Gioia, D.A, and Chittipeddi, K, 1991, Sensemaking and Sensegiving in Strategic Change Initation, Strategic Management Journal, vol. 12, No. 6, pp. 433-448.

Gioia, D.A, et al, 2012, Seeking Qualiative Rigour in Inductive Research; Notes on the Gioia Methodology, Organisational Research Methods, vol. 16, No. 1, pp. 15-31.

Goddard, W and Melville S, 2011, Research Methodology: An Introduction (2nd Edition), Juta \& Co. Ltd, Lansdowe.

Guenther, J et al, 2020, Digital inclusion in central Australia: what is it and what makes it different?, Rural Society.

Harrison H, et al, 2017. Case Study Research: Foundations and Methodological Orientations, Forum Qualitative Sozialforschung/forum: Qualitative Social Research, vol. 18, No. 1, pp. 1-17.

Helsper, E.J, and Eynon, R, 2013, Distinct skill pathways to digital engagement, European Journal of Communication, vol. 28 , No. 6 , pp. 696-713.

Hendry, J, 2020, How Aussie Schools Are Preparing for a COVID-19 Shutdown, Available from: https://www.itnews.com.au/news/how-aussie-schools-are-preparing-for-a-covid-19-shutdown-539770

Lamb, S, et al, 2014, Educational Disadvantage and Regional and Rural Schools, Quality and Equity: What Does Research Tell Us?, Adelaide Australia, pp. 65-71.

Landauer, T.K, et al, 1998, An Introduction to Latent Semantic Analysis, Discourse Processes, vol. 25, pp. 259-284.

Moore, S and Hodges, C.B, 2020, So You Want to Temporarily Teach Online, Inside Higher Education, Available: https://www.insidehighered.com/advice/2020/03/11/practical-advice-instructors-faced-abrupt-move-online-teachingopinion, retrieved: 10 October 2020 .

Program for International Student Assessment (PISA) 2003, Learning for Tomorrow's World, OECD, Available from: http://www.oecd.org/education/school/programmeforinternationalstudentassessmentpisa/34002216.pdf

Sacks, D et al, 2020, COVID-19 and Education: How Australian Schools are Responding and What Happens Next, Price Waterhouse Cooper.

Schleicher A, 2020, The Impact of COVID-19 on Education: Insights from Education at a Glance 2020, OECD, pp.1-31.

Shernoff, D.J et al, 2016, Student engagement as a function of environmental complexity in high school classrooms, Learning and Instruction, vol. 43, No. 1, pp. 52-60.

Van Acker, F et al, 2013, Why teachers share educational resources: A social exchange perspective, In McGreal R, Kinuta $\mathrm{W}$ and Marshall S, Perspectives on open in distance learning, Athabasca University, Canada.

Virtanen, $\mathrm{T}$ et al, 2015, The relationship between classroom quality and students' engagement in secondary school. Educational Psychology, vol. 35, No. 8, pp. 963-983.

Vygotsky, L.S, 1926, Educational psychology, Saint Lucie Press, Jamaica Hills, NY.

Weigel, M et al, 2010, New Digital Media and Their Potential Cognitive Impact on Youth Learning, In: Khine, M.S, and Saleh (eds), I.M, New Science of Learning, Springer, New York.

Wyse, A.E et al, 2020. The Potential Impact of COVID-19 on Student Learning and How Schools Can Respond, Educational Measurement: Issues and Practice, Vol. 39, No. 3, pp. 60-64.

Zagon, C, 2020, Coronavirus Schools Victoria: Online Learning to Begin From Term 2 and Changes to VCE, Available from: https://www.9news.com.au/national/coronavirus-schools-victoria-online-learning-to-begin-from-term-2-andchanges-to-vce/b03e145a-c757-4970-91b5-1c5008877ca7 